\title{
Locking Vs Buttress Plating in Management of Fracture Upper End of Tibia
}

\author{
Dr H S Mann ${ }^{1}$, Dr Girish Sahni², Dr Arvind Kumar ${ }^{3}$, Dr Ashok Kumar Sharma ${ }^{4}$ \\ ${ }^{1}$ Associate Prof, ${ }^{2}$ Assistant Prof, ${ }^{3}$ Senior Resident, ${ }^{4}$ Junior resident \\ Corresponding Author \\ Dr Girish Sahni \\ 94-Ajit Nagar, Patiala147001, Punjab INDIA \\ Email: sawhneygirish@gmail.com
}

\begin{abstract}
Introduction- Fractures of proximal tibia involves a major weight bearing joint i:e knee joint and are serious injuries that frequently result in functional impairment. To preserve normal knee function surgeon must try to maintain joint congruity, preserve the normal mechanical axis, ensure joint stability and restoring full range of motion.

Aim- the goal of study was to compare the restoration of articular congruity, axial alignment, joint stability and functional motion.

Material and Methods- A study was conducted on 30 patients of fracture of upper end tibia in adults out of which 15 cases were treated by locking plate and the rest 15 cases were treated by buttress plating

Results- Road side accidents were the cause in more in $90 \%$ of patients. According to AO classification 14 cases were type A, 5 cases were type $B$ and 11 cases were type $C$. Intra articular fractures were commonly Schatzker type VI. Duration of surgery and rate of complications were more in buttress plate group. Radiological union occurred earlier in patients treated with locking plate. One case that went into non union was seen in buttress plate group. Early mobilitiy and better functional outcome was seen in those treated with locking plate than those with buttress plate.

Conclusions- Our study concluded that proximal tibial fractures can be treated more effectively with lateral locking plate.

Keywords:- tibia, buttress plate, locking plate, fracture, non union.
\end{abstract}

\section{INTRODUCTION}

High velocity traffic in this modern age has resulted in broken bones in different patterns. By its very location, the tibia is exposed to frequent injury, it is the most common fractured long bone. Because most of tibial surface is subcutaneous throughout its length, open fractures are more common in the tibia than in any other major long bones. Furthermore, the blood supply to tibia is more precarious than that of bone enclosed by heavy muscles. ${ }^{1}$ Higher speed injuries in younger patients from sports or similar mechanism can cause split fracture or rim avulsion fractures associated with ligament injuries. Motor vehicle accidents and fall from heights ${ }^{2-7}$ and pedestrian struck injuries often produce more severe patterns, which may involve both condyles and have a high risk for associated neurovascular injury, 
compartment syndrome, and communicating open wounds. ${ }^{8,9}$

The Schatzker classification system focuses on standard tibial plateau fractures. However, higher Schatzker fracture rankings may represent fracture-dislocations and are predictive of significant associated soft-tissue injury.

The Schatzker classification is based on the idea that "certain pathoanatomic and etiological factors as well as therapeutic features demand that certain injury types be grouped together". ${ }^{[10,11]}$ In the Schatzker classification, each increasing numeric fracture category indicates increasing severity, reflecting not only increased energy imparted to the bone at the time of injury but also an increasingly worse prognosis. Therefore, orthopedic surgeons find the Schatzker classification useful in assessing the initial injury, planning management, and predicting prognosis. The Schatzker classification system divides tibial plateau fractures into six types: lateral tibial plateau fracture without depression (I), lateral tibial plateau fracture with depression (II), compression fracture of the lateral (IIIA) or central (IIIB) tibial plateau, medial tibial plateau fracture (IV), bicondylartibial plateau fracture (V), and tibial plateau fracture with diaphyseal discontinuity (VI). The first three types (I, II, and III) are typically the result of low-energy injury. ${ }^{[12,13]}$ The second three types (IV, V, and VI) are typically the result of high-energy injury. However, relatively low-energy trauma to osteoporotic bones may produce fracture patterns similar to those of high-velocity injuries. ${ }^{[14]}$ The magnitude of the force determines both the degree of fragmentation and the degree of displacement Fractures of proximal tibia involves a major weight bearing joint i:e knee joint and are serious injuries that frequently result in functional impairment. To preserve normal knee function surgeon must try to maintain joint congruity, preserve the normal mechanical axis, ensure joint stability and restoring full range of motion. There are two categories of proximal tibia fractures articular and non articular. Articular fractures, termed tibial plateau or tibial condylar fractures, affecting knee alignment stability and movement. Non-Articular fractures affect knee alignment, stability and strength. ${ }^{15}$ The aim of surgical treatment of proximal tibia is to restore and preserve normal knee function.

The majority of tibial plateau fractures are secondary to high speed The motor vehicle accidents and fall from heights. The proximal tibia is most likely to be subjected to a valgus force because of the normal 5 to 7 degrees of valgus alignment of the knee and because of propensity to be struck from lateral side. A combination of valgus and axial compression produces lateral side depression, split depression or less commonly, lateral split or total lateral condyle fracture ${ }^{16}$. Knee flexion, varus and internal rotation of medial femoral condyle produces posteromedial shearing fractures of medial plateau as isolated split fractures or as bicondylar fracture ${ }^{17}$.

Fibula influences anatomical behaviour of condylar fractures. Isolated fractures of lateral condyle with an intact fibula donot collapse further because of support of fibula. Conversely, fracture of lateral condyle with associated fibular fractures tend to collapse into valgus because of lack of fibular support. Bicondylar fractures donot collapse or angulate when proximal fibula is fractured and displaced, however if the fibula is intact, the medial condyle collapses producing varus deformity. ${ }^{18}$

Accurate reduction of articular surface is important aspect of treating displaced plateau fractures. Plate osteosynthesis is recognised as treatment of choice for these fractures. Locking plate system converts the shearing forces at implant into compressive forces at screw bone interface whereas contoured buttress plates rigidly hold the fractured fragments in place.

\section{MATERIAL AND METHODS}

The present study was conducted on 30 patients between 18 to 70 years, of fracture of upper end tibia closed/ open Gustillo Anderson grade I and II ${ }^{19}, 15$ cases were treated by locking plate and rest 
15 with buttress plate. Suitable $\mathrm{X}$ rays were done to assess the type of fractures, degree of displacement and involvement of articular surface. Fractures were approached with either anterolateral $^{20}$ or posteromedial ${ }^{21}$ approaches, as the need be, under tourniquet control with or without bone grafting.

In Anterolateral approach patient was placed in semi lateral position and limb is exanguinated. After clean and draping a longitudinal incision over the anterior edge of fibula the bone is exposed after superficial dissection. The fracture is reduced and provisionally fixed with $\mathrm{k}$ wires. Definite fixation with either buttress or locking plate is done. Wound closed in layers after obtaining hemostasis and in postero medial approach a longitudinal incision on lateral border of gastrocnemius was made of desired length and after superficial dissection the bone was exposed and fracture fragments reduced and provisionally fixed with $\mathrm{k}$ wires. Definite fixation with either buttress or locking plate is done. Wound closed in layers after obtaininghaemostasis and ASD done. Partial weight bearing was allowed after 4-8 weeks depending on radiographic evidence of healing and graft incorporation. All the patients were followed for a minimum of 9 months with regular checkup done at 3 weeks, 6 weeks, 12 weeks, then monthly for 3 months and finally at $9^{\text {th }}$ month. Result evaluation was done as per criteria laid down bySavoie et.al $1987 .{ }^{22}$

\section{RESULTS}

Inthis study maximum patients i:e 14(46.66\%) were in the age group of 31 to 50 years of age followed by $7(23.33 \%)$ patients in the age group of 21 to 30 years. $90 \%$ of the patients were males and right leg being involved in $66.66 \%$. Road traffic accidents were major mode of injury accounting for $93.33 \%$ of total cases. 20 cases $(66.66 \%)$ had closed fractures while 10 cases $(33.33 \%)$ were of open fractures with majority (i.e. 6 cases) having puncture wounds and 4 cases had laceration $>1 \mathrm{~cm} .14$ cases were AO type A, 5 were type $B$ and 11 were type C. Most of the intraarticular fractures were Schatzker type VI. The mean duration of surgery for locking plate was $56.13 \mathrm{~min}$ (Range 42-85) and for buttress plating was 69.4 min s(Range 45-90).In locking plate group wound healing occurred primarily with healthy scar formation in $86.66 \%$ cases while in $13.33 \%$ there was superficial infections which healed with antibiotics. In buttress plate group wound healing occurred primarily in $66.66 \%$ cases, $20 \%$ cases showed superficial infections which healed with antibiotics while in $13.33 \%$ cases there was deep infection which healed after removal of implant. Full weight bearing was allowed to patients after duration of 15-26 weeks. In locking plate group most of the cases, weight bearing was possible at mean of 18.13 weeks. In buttress plating most of the cases weight bearing was possible at mean of 20.57 weeks.

Radiological union in locking plate group occurred between 13-16 weeks mean (16 weeks) in $66.66 \%$ cases while in buttress plating group at $15-18$ mean (17.40 weeks) in $60 \%$ cases. Loss of reduction ( 2 cases) and non-union (1 case) was seen more in buttress group, while none in locking plate. Malunion was seen in 1 case of locking plate and 2 cases of buttress plating. Zero degree extension gap to $\geq 110^{\circ}$ flexion in Locking plate group was $(66.66 \%)$ while in buttress plating was (46.66). $0-5^{\circ}$ extension gap to $90-110^{\circ}$ flexion in locking group was $26.66 \%$ while in buttress plating group was $33.33 \%$.According to Savoie et.al ${ }^{11}$ criteria $93.33 \%$ cases had excellent to good results in locking plate group while $80 \%$ in buttress plate group.

Table no. 1 Showing Time When Full Weight Bearing Was Allowed

\begin{tabular}{|l|l|l|l|l|}
\hline $\begin{array}{l}\text { FWB } \\
(\text { weeks })\end{array}$ & \multicolumn{2}{|l|}{ LOCKING PLATE } & \multicolumn{2}{|c|}{$\begin{array}{l}\text { BUTTRESS } \\
\text { PLATE }\end{array}$} \\
\hline & No. & $\begin{array}{l}\text { Percentage } \\
(\%)\end{array}$ & $\begin{array}{l}\text { No } \\
.\end{array}$ & $\begin{array}{l}\text { Percentage } \\
(\%)\end{array}$ \\
\hline $10-15$ & 2 & 13.33 & 0 & 0.0 \\
\hline $16-20$ & 11 & 73.33 & 10 & 66.66 \\
\hline $20-25$ & 2 & 13.33 & 2 & 13.33 \\
\hline$>25$ & 0 & 0.0 & 2 & 13.33 \\
\hline Non-union & 0 & 1 & 1 & 06.66 \\
\hline Total & 15 & 100.0 & 15 & 100.0 \\
\hline
\end{tabular}


Table no. 2. Showing Time Taken For Radiological Union

\begin{tabular}{|l|l|l|l|l|}
\hline $\begin{array}{l}\text { Periods } \\
\text { of } \\
\text { weeks }\end{array}$ & \multicolumn{2}{|c|}{ Locking plate } & \multicolumn{2}{c|}{ Buttress plate } \\
\hline & No. & Percentage(\%) & No. & Percentage(\%) \\
\hline $11-14$ & 5 & 33.33 & 3 & 20.00 \\
\hline $15-16$ & 5 & 33.33 & 3 & 20.00 \\
\hline $17-18$ & 3 & 20.00 & 6 & 40.00 \\
\hline$>18$ & 2 & 13.33 & 3 & 20.00 \\
\hline Total & 15 & 100.0 & 15 & 100.0 \\
\hline
\end{tabular}

Table no 3. Showing Complications

\begin{tabular}{|l|l|l|l|l|}
\hline \multirow{2}{*}{$\begin{array}{l}\text { Wound } \\
\text { healing }\end{array}$} & \multicolumn{3}{|l|}{ Locking plate } & \multicolumn{2}{|l|}{ Buttress plate } \\
\cline { 2 - 5 } & No. & Percentage & No. & Percentage \\
\hline Malunion & 1 & 06.66 & 2 & 13.33 \\
\hline Non - union & 0 & 0.0 & 1 & 06.66 \\
\hline $\begin{array}{l}\text { Loss of } \\
\text { reduction }\end{array}$ & 0 & 0.0 & 2 & 13.33 \\
\hline $\begin{array}{l}\text { Shortening> } \\
2 \mathrm{~cm}\end{array}$ & 1 & 06.66 & 1 & 06.66 \\
\hline
\end{tabular}

\section{DISCUSSION}

Operative intervention is treatment of choice for fractures involving upper end tibia in order to attain anatomical reduction and joint congruity with the goal to achieve a stable and painless joint with a normal range of motion and function. Various studies and literature compare the locking plate and buttress plate in the treatment of this fracture but controversy still exist. The Locking plate system consists of a pre-contoured, anatomically shaped plate that can be inserted with a minimally invasive technique and of screws that can be locked within the plate. Biomechanical testing has shown that these plates demonstrate elastic deformation equal to that of conventional plates (lateral buttress and medial antiglide constructions). These plates can also simultaneously achieve fixation of an associated metaphyseal/diaphyseal component of the fracture with a minimal approach.

In our study average age of these patients was 41.06 years showing that these fractures affect adults in the prime of their productive life. Men were commonly involved because of their outdoor activity and majority of motor vehicles are driven by males. Right limb affection merely reflects a coincidence depending upon the position of limb at the time of injury. $93.33 \%$ of cases were due to road accidents which is due to increased vehicular traffic worldwide. Most of the intraarticular fractures were type Schatzker typeVI ${ }^{23}$ because of high velocity trauma. The difference between mean duration of surgery for locking and buttress plating was not statistically significant but comparable ( $\mathrm{p}$ value is 0.99 by unpair $\mathrm{t}$ test. Sharma et al). ${ }^{24}$ Less intra operative time for locking plate is due to less time spent for plate contouring. More complications and deep infections were seen in buttress plate group due to extensive soft tissue dissection and medial placement of plate directly beneath the skin. The difference between the time taken for radiological union in both the groups were statistically insignificant ( $p$ value is 0.94 . egol et al $2004 .^{25}$ however less time in locking group was because of less tissue dissection needed and due to indirect reduction technique, the fracture biology is maintained. Loss of reduction and, non union, malunion was higher in buttress plategroup while $100 \%$ union was achieved in locking plate group. incidence of knee stiffness was higher in buttress plate group due to delayed start of postop rehabilitaion due to longer incision and more soft tissue dissection. Early post op complication like superficial infection, deep infection, hardware pain and skin slough more in buttress plate group (13.33\% with locking plate where as $33.33 \%$ with buttress plate.) Probably due to extensive soft tissue dissection and medial placement of plate directly beneath the skin. ( $p$ value is 0.76 by unpaired $t$ test). Various studies done by lee et $\mathrm{al}^{[26]}$ moore ${ }^{[27]}$ and gosling et $\mathrm{al}^{[28]}$, all have substantiated these facts..

Excellent to good results were obtain ed in 93.33\% cases in locking plate group and in $80 \%$ cases in buttress plate group. Thus, locking plate technique is a better technique compared to traditional plating as it involves smaller incision, lesser soft tissue dissection and a much stronger construct. This in turn leads to lesser complications with early fuctional recovery. 


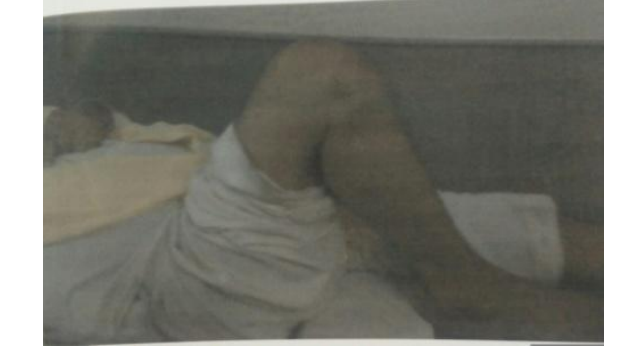

Functional movements after union

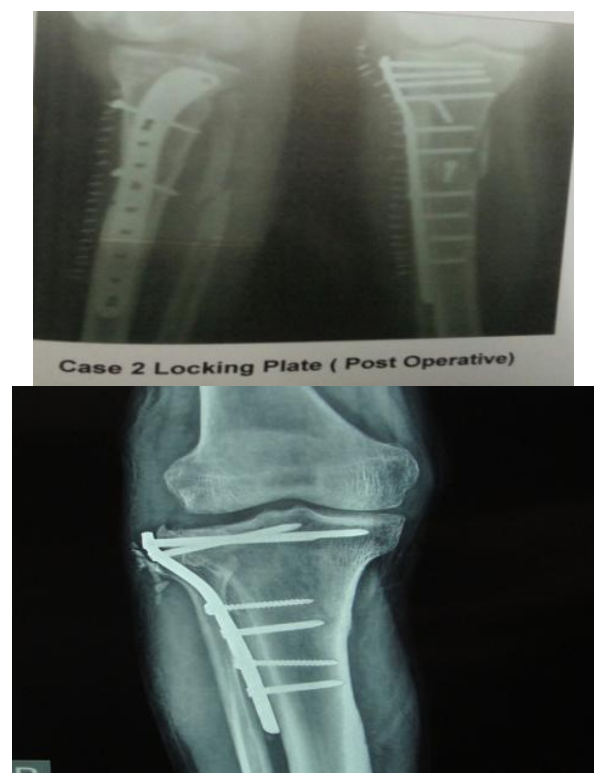

Buttress Plate

\section{CONCLUSION}

we have observed from above findings that in locking plate healing occurred primarily with healthy scar formation in $86.66 \%$ cases while in $13.33 \%$ there was superficial infections only, while in buttress plate group wound healing occurred primarily in $66.66 \%$ cases, $20 \%$ cases showed superficial infections, while in $13.33 \%$ cases there was deep infection which healed after removal of implant. In locking plate group most of the cases, weight bearing was possible at mean of 18.13 weeks. In buttress plating most of the cases weight bearing was possible at mean of 20.57 weeks. Radiological union in locking plate group occurred between 13-16 weeks mean (16 weeks) in $66.66 \%$ cases while in buttress plating group at $15-18$ mean (17.40 weeks) in $60 \%$ cases. From our study, we observed that proximal tibia fractures can be better and more effectively treated with lateral locking plate as compared to buttress plate. Early rehabilitation, fewer complications, early radiological union and early weight bearing with better and near complete functional recovery is seen with locking plate.

Our study concludes that locking plate is better implant than buttress plate in management of proximal tibia fractures.

Ethical approval: study is in accordance with the ethical standards of the institute.

Informed consent: was obtained.

Conflict of interest:- nil.

Source of funding:- nil.

\section{REFERENCES}

1. Whittle AP, Wood II GW. Fractures of lower extremity in: Campbell's operative Orthopaedics $10^{\text {th }}$ ed. USA: Mosby; 2003.2754.

2. Honkonen SE, Jarvinen MJ. Classification of fractures of the tibial condyles. $\mathrm{Br} \mathrm{J}$ Bone Joint Surg 1992;74(6):840-847.

3. Honkonen SE. Indications for surgical treatment of tibial condyle fractures. Clin Orthop 1994;(302):199-205

4. Burri C, Bartzke G, Coldewey J, Muggler E. Fractures of the tibial plateau. Clin Orthop 1979;138:84-93

5. Segal D, Mallik AR, Wetzler MJ, Franchi AV, Whitelaw GP. Early weight bearing of lateral tibial plateau fractures. Clin Orthop 1993;(294):232-237

6. Schulak DJ, Gunn DR. Fractures of tibial plateaus. Clin Orthop 1975;109(June):166177

7. Blokker $\mathrm{CP}$, Rorabeck $\mathrm{CH}$, Bourne RB. Tibial plateau fractures. ClinOrthop 1984;182:193-199.

8. Marsh JL, Smith ST, Do TT. External fixation and limited internal fixation for complex fractures of the tibial plateau. J Bone Joint Surg Am 1995;77A:661-673.

9. Barei DP, Nork SE, Mills WJ, Coles CP, Henley MB, Benirschke SK. Functional outcomes of severe bicondylartibial plateau fractures treated with dual incisions and medial and lateral plates. J Bone Joint Surg Am 2006; 88A:1713-1721 
10. SchatzkerJ, McBroom R, Bruce D. The tibial plateau fracture: the Toronto experience, 1968-1975. Clin Orthop Relat Res1979; 138: 94-104. Medline

11. SchatzkerJ. Compression in the surgical treatment of fractures of the tibia. Clin Orthop Relat Res1974; 105: 220-239. Medline

12. WatsonJT, Schatzker J. Tibial plateau fractures. In: Browner BD, ed. Skeletal trauma: basic science, management, and reconstruction. 3rd ed. Philadelphia, Pa: Saunders, 2003; 2047-2130.

13. TscherneH, Lobenhoffer P. Tibial plateau fractures: management and expected results. Clin Orthop Relat Res1993; 292: 87-100. Medline

14. SuEP, Westrich GH, Rana AJ, Kapoor K, David HL. Operative treatment of tibial plateau fractures in patients older than 55 years. Clin Orthop Relat Res2004; 421: 240-248. CrossRef, Medline

15. Watson JT, Wiss DA. Fractures of proximal tibia and fibula in:Rockwood and Green's fractures in adults $5^{\text {th }}$ ed.

16. Lobenhoffer P, Schulze M, GerichT. Closed reduction/percutaneous fixation of tibialplateau fractures: arthroscopic versus fluoroscopic control of reduction. J O)rthop Trauma 1999;13:426-431

17. Barei DP, O'Mara TJ, Taitsman LA, Dunbar RP, NorkSE.Frequency and fracture morphology of the posteromedial fragment in bicondylartibial plateau fracture patterns. JOrthop Trauma2008;22:176-182

18. Sarmiento A, sharpe FE, Ebramzadeh E, normand $\mathrm{P}$, shankwiler J. Factors influencing the outcome of closed tibial fractures treated with functional bracing. Clin orthoprelat res 1995;315:8.

19. Yu Z, Zheng L, Zhang Y, Li J, Ma B. Functional and radiological evaluation of high energy tibial plateau fractures treated with double buttress plate fixation. Eur J Med Res. 2009 May 14;14(5):200-5.
20. Lindvall E, sanders R, Dipasquale $T$, Herscovinci D, Haidukewych G, Sagi C. Intramedullay nailing versus percutaneous locked plating of extra-articular proximal tibial fractures: comparison of 56 cases. J Orthop Trauma. 2009 Aug;23(7):485-92.

21. Ehlinger M, Adam P, Bonnomet F. Minimally invasive locking screw plate fixation of non-articular proximal and distal tibialfractures .orthop Traumatolsurg Res 2010 Nov;96(7):800-9. Epub 2010 Sep 18.

22. Moore TM, Patzakis MJ, Harvey JP. Tibial plateau fractures:definition, demographics, treatment rationale and long term results of closed traction management or operative reduction. J orthop Trauma 1987;1:97.

23. Schatzer J, McBroom R, Bruce D. The tibial plateau fracyures: the Toronto experience 1968-1975. Clin Orthop 1979;138:94-104.

24. Sharma R, Kapila R, Singh BP, Sohal YS. Traditional buttress plating v/s MIPO in management of proximal tibial fracturesA clinical study. Punjab Journal Of Orthopaedics Vol XIV,No-I, Dec 2013 pg 11-16

25. Bhattacharyya T, McCarty LP3rd, Harris MB. The posterior shearing tibial plateau fractures: treatment and results via a posterior approach. J Orthop Trauma 2005;19:305-310.

26. Higgins TF, klatt J, Bachus $\mathrm{KN}$. Biomechanical analysis of bicondylartibial plateau fixation : how does lateral locking plate fixation compare to dual plate fixation? J Orthop Trauma 2007 May; 21(5):301-6

27. Jensen DB, Rude C, Duus B. Tibial Plateau factures. A comparision of conserveative and surgical treatment. J Bone Joint Surg Br 1990; 72B:49-52.

28. Goyal KS, Skalak AS, Marcus RE, vallier HA, Cooperman DR. Analysis of anatomic periarticulartibial palte fit on normal adults, Clin Orthop Relat Res 2007; 461:245-257. 